\title{
HLA-DR52 Antigen
}

National Cancer Institute

\section{Source}

National Cancer Institute. HLA-DR52 Antigen. NCI Thesaurus. Code C71272.

HLA-DR52 antigen is a set of polymorphic glycoproteins encoded by the human HLADRB3 gene. This protein is the beta subunit of the major histocompatibility complex, class II DR protein, which is expressed primarily in lymphoid cells and functions to present antigens for CD4+ T lymphocytes. 